\title{
Mental Health Protection and Health Policy Towards People with Mental Illnesses. the Case of Poland
}

\author{
Małgorzata Dobrowolska \\ Assistant Professor, Institute of Psychology, University of Silesia in Katowice
}

Bernadetta Izydorczyk

Assistant Professor, Institute of Applied Psychology, Jagiellonian University in Cracow

\begin{abstract}
The aim of the article is to present basic data on the health policy in Poland for the years 2016-2020 in the context of current standards and developmental goals for mental health promotion in the European Union countries. The article is also aimed at adumbrating standards and directions in mental health protection. It also sets out to present guidelines for helping people with mental illnesses that are based on the results of our research. This work presents selected results of a study which was carried out within the "Diagnosing the aid and social support system for people with mental illnesses in the Mazovia Province" research project. The project was co-financed from the resources of the Human Capital Operational Programme (as part of European Union's European Social Fund).
\end{abstract}

Keywords: mental health protection, health policy towards people with mental illnesses

\section{Introduction}

Mental health protection and the health policy towards Poles that is planned for the upcoming years are closely linked with a need to diagnose the aids and social support system, also for people with mental illnesses.

The aim of the article is to present basic data on health policy in Poland for the years 2016-2020 in the context of current standards and developmental goals for mental health promotion in the European Union countries. The article is also aimed at adumbrating standards and directions in mental health protection. It also sets out to present guidelines for helping people with mental illnesses that are based on the results of our research.

The epidemiological and demographic analyses for Poland that can be found in subject literature indicate that the number of people in the working and pre-working age groups will decrease in the upcoming years, while the number of people in the post-productive age group will systematically increase (2008-2035 population projection for Poland, Central Statistical Office of Poland, 2008; National Strategic Framework. Policy Paper for the protection of health for the period 2014-2020, 2015.) Epidemiological analyses reveal that Polish people's health state is worse than the European Union average. This is true for both males and females. A higher fatality level results from the risks of circulatory diseases and cancer. Incapacity for work is most often linked with diseases such as: circulatory $(16.2 \%)$, mental and behavioral disorders (15.9\%), nervous system diseases $(9.5 \%)$ and others. The analyses above underline the significance of the development of mental disorders in the future Polish populace.

The cohesion policy that embraces health policy and mental health protection in all European Union states imposes a necessity to support standards that stimulate an all-encompassing and coordinated approach to mental health protection. These standards were listed in the "Europe 2020" strategy. They were also adopted by the Coordinating Committee on Development Policy and approved by the Ministry of Health on 8 July 2015 in the form of the "National Strategic Framework: Policy Paper for the protection of health for the period 2014-2020" document. It was approved by the Ministry of Health on 8 July 2015.

Apart from the mentioned document, the Regulation of the Council of Ministers of 5 January 2015 on the National Programme for the Protection of Mental Health also regulates protecting the rights of people with mental illnesses and the 
rules of looking after them. On the grounds of article 2, paragraph 6 of the Act on Mental Health Protection (Polish Journal of Laws 2011, No. 231, item 1375 and Polish Journal of Laws 2015, item 1916), §1.1. establishes the National Programme for the Protection of Mental Health for 2016-2020. The National Programme for the Protection of Mental Health outlines basic standards for actions taken in the process of prophylaxis and dealing with people with mental disorders and various emotional difficulties. The program also maps out a strategy for taking actions aimed at providing people with mental disorders with a complex, multisided and publicly available assistance that is fitted for health needs and located near the people's place of residence. Apart from the mentioned documents that protect the rights of patients with mental illnesses, those rights and rules for dealing with people with mental disorders are also outlined in the Act on Mental Health Protection of 1994.

All the documents and programs mentioned in this article point out a necessity to respect developmental goals. In order to enable meeting these goals, specialized psychology professionals, both from the field of adult and child psychology, need to be included in the process of attaining them.

\section{A diagnosis of the aid and social support system for people with mental illnesses: A selection of conclusions from empirical research. The case of Poland.}

The study was carried out among representatives of institutions that provide help and social support for people with mental illnesses, namely: medical personnel of mental health protection service providers in the Mazovia Province, heads of communal homes of mutual aid and occupational therapy workshop centers, therapists employed in communal homes of mutual aid and occupational therapy workshop centers who perform tasks related to supporting people with disorders, people with mental illnesses, people from the environments of patients with mental illnesses, psychiatrists employed in hospitals and psychiatric wards, directors and heads of communal homes of mutual aid that provide support to people with mental illnesses as well as therapists employed in communal homes of mutual aid who work directly with people with mental illnesses.

The research employed both qualitative (desk research and 52 individual in-depth interviews) and quantitative methods (369 telephone-based computer-aided interviews).

People with mental illnesses and their families have relatively sufficient possibilities to utilize specialist medical and paramedical support in most provinces. As for the twenty-four-hour and interim (interventional) care service providers for various types and causes of disorders (ranging from decompensated addicts to patients going through disease episodes and people in remission who visit health resorts), they are relatively diverse and numerous, offering a relatively high number of beds available to both current and awaiting patients as well as the presence of collaborating institutions in a given institution's surroundings. Offering such care is a convenience to families of people with mental illnesses-they can expect institutional care for their charges. Institutional care is extended to the family member who suffers from an illness for numerous reasons, among others-to their family's convenience.

Blanket registration of people with mental illnesses, in compliance with DSM IV (ICD 10 in Poland) hinders the possibility to carry out thorough analyses and aggregate data for each county. Introducing an additional system of monitoring the issue of mental disorders should be considered. Such a system would allow obtaining plausible statistic results in compliance with the prerequisite to protect sensitive data. According to most recent statistics, over $70 \%$ of the people with mental disorders who are treated within outpatient care are patients of mental health outpatient clinics. In the period between 1997 and 2010 the total number of patients and the number of patients treated for the first time within outpatient care almost doubled (in both cases there was a growth of over $70 \%$ ) in all Polish provinces. The number of cases diagnosed with mental disorders has been systematically growing in each year from the period of 2010-2012 up to now. The most commonly diagnosed groups among the treated patients are neurotic and schizophrenic disorders, followed by mood disorders and organic mental disorders. Patients treated for alcohol disorders make up the fourth most numerous group.

According to the Diagnosis of the social support system for people with mental disorders within support and social integration services in Mazovia, the most prevalent groups of specialist care services for people with mental disorders are, namely: teaching and shaping skills that are essential for unassisted functioning, interventions and help targeted at functioning within a family, helping with official errands, supporting and helping with finding employment, assisting with dealing with money, treating the disordered body functions and housing aid. 
The study allowed the identification of most significant barriers and problems for providing social support, including social and vocational support for people with mental illnesses. These barriers can be divided into several domains:

Economic barrier-i.e., a lack of sufficient financial resources, which resources would enable offering more effective support to people with illnesses and their caretakers: limited amounts of time at the support-providers' disposal; few institutions/units that provide environmental support; a lack of supervised apartments; limited access to specialists (e.g., psychotherapists);

Barrier of specialist care providers-i.e., it is related with proper training on behalf of the staff employed in institutions that provide support to people with illnesses and their caretakers; medical and social care staff frequently lack the knowledge, competences or skills of these institutions' employees.

Barrier of social stereotypes-i.e., low level of knowledge about mental illnesses within the population; stereotypical approach to people with illnesses; lack of understanding combined with anxiety and reluctance in the society towards people with illnesses and their caretakers;

Barrier of lacking employment and permanent employee benefits-i.e., lack of job positions for the people with mental illnesses who are able to work;

Barrier of lacking access to information-i.e., lack of informational and educational support for caretakers of people with illnesses (low effectiveness of the system that provides information about possible aid sources and forms available for people with illnesses and their caretakers);

Barriers related with the patients' environment-i.e., caretakers' health problems that hinder looking after their close ones with illnesses and the possibilities to make use of aid; impeded contact with the patients' families; shame and anxiety on behalf of the patients' nearest environment towards making use of aid and a lack of motivation for seeking sources of support;

Barriers related with the patient's current health state-i.e., patients health state that may hinder social and vocational activities; lack of motivation among people with mental illnesses; problems with communicating with people with diseases; patients' fear of seeking and using help.

Legal and administrational barriers-i.e., limitations resulting from the existing law; difficulties with inter-institutional and inter-organizational collaboration.

Based on the conducted interviews, in order to remove the mentioned barriers we suggest the following measures:

Providing more funding for the mental health protection system, which would lead to offering more effective help to people with illnesses and their caretakers; involving volunteers, interns, apprentices and the patients' environments in actions carried out by the institutions; seeking various forms of funding and subsidizing the services; shortening the time during which patients wait for support; setting up centers that provide help for people with illnesses and their caretakers;

Educating competent employees of the healthcare and social care systems, improving qualifications and providing further training; increasing the access to free trainings for the employees of institutions that provide support for people with illnesses; supervising one's own work and analyzing cases together with other staff members in a given institution;

Carrying out information and awareness campaigns targeted at the whole society; holding events, meetings, exhibitions, cultural outings and visiting nature-i.e., creating opportunities for meeting healthy people;

Organizing actions aimed at informing employers; providing people with illnesses with internship possibilities; holding training sessions on running official errands and preparing application documents; providing people with mental illnesses with support from an assistant or trainer, who would support them in their workplaces; organizing job fairs; holding workshops aimed at developing skills;

Providing information and educating the environments of people with mental illnesses;

Maintaining contact with patients' families, explaining and justifying the need for support and its validity; providing aid from qualified caretakers/assistants for caretakers who are unable to look after the patients themselves 
Providing psychological and psychiatric support for people with mental illnesses; organizing collaboration between people with mental illnesses in the form of meetings (group therapy); working with patients on their long-term plans; creating longterm therapeutic programs;

Creating a system of ties between the various institutions and organizations that provide support for people with mental illnesses, thus, expanding the range of services provided in each province; fostering intra-team collaboration within each institution; enabling collaboration between individual specialists and external institutions; improving communication between units.

Establishing task forces that work together to the benefit of people with mental illnesses and their families; this would allow adjusting treatment methods and therapy to patients' social situations. A possibility to consult within a task force allows a more precise and accurate diagnosis and monitoring the progress made by patients and their environment, which translates into a higher treatment effectivity. Moreover, the interdisciplinary nature of these teams would enable making full use of the potential of various institutions and organizations, whose actions are aimed at people with mental illnesses.

The study also allowed the identification of training needs that were raised by employees of institutions providing support for people with mental illnesses. Those needs concerned trainings aimed at acquiring knowledge and skills with respect to providing support for such people and for their caretakers in order to allow people with mental illnesses function independently within the local community.

People with mental illnesses identified increasing the understanding and awareness in their environments and being provided with more intense therapeutic support as their biggest needs with regard to the social support that is provided to them. People who look after their loved ones pointed to such needs as a possibility to acquire the skills of supporting people with illnesses, receiving help from a third party who would support them with their skills and knowledge, and obtaining psychological and motivational support. As for the needs concerning qualifications improvement with regard to providing support, also in the form of social and professional activation, that are raised by caretakers of people with mental illnesses, the obtained data suggests highest prominence of the following: expanding knowledge on the ailments that people with mental illnesses suffer from, acquiring the skill of communicating with people with illnesses as well as obtaining informational support concerning the available sources and types of help. An equally important factor that enables people with mental illnesses and their families to function properly is being aware of their own rights. The regulations in force are aimed at enabling people with mental illnesses and people from their environments to participate in social life as actively as possible. The implementation of these tenets requires increasing the accessibility of information on the prerogatives of people with mental illnesses and their families. It is a fundamental task in the context of utilizing the already existent forms of support available for the described social group. The prerogatives of people with mental illnesses and their families are often not exercised due to a lack of awareness of their existence.

The presented study has revealed that people with mental illnesses often times hold negative perceptions of their situation with regard to maintaining social relationships due to a low level of acceptance which is faced by people with illnesses within the society. People with mental illnesses frequently feel rejected and misunderstood by their environments. Consequently, they shut themselves and often times begin to withdraw from contacts. The social activity of people with mental illnesses depends on the type and stage of illness. People with illnesses mostly care about maintaining social relationships. However, in most cases those relationships are limited to their closest environments (i.e., family and closest friends). In case of some illnesses people who suffer from them face periods of higher or lower social activity. Subjects of the presented study evaluated interpersonal contacts higher in the situation of being in communal homes of mutual aid due to the fact that it is possible to meet specialists and other people with illnesses there.

The situation is slightly better for caretakers of people with mental illnesses. Those caretakers are usually satisfied with their social relationships. They strive to maintain contacts with others, even though it is often times difficult due to a multitude of obligations. Looking after a person with a mental illness translates in a certain way into the caretaker's social relationships. As a result, these people frequently feel alienated and misunderstood by their environments. They are ashamed of their situation and problems; sometimes they even withdraw from contacts and avoid them. It also happens that caretakers are isolated by their environments. 
In order to increase the level of people with mental diseases and their caretakers' satisfaction with their social relationships, the following measures should be taken: increasing the access to healthcare, i.e. diagnostic and therapeutic support; support should be provided by people with proper qualifications and predispositions

the topic of mental illnesses and the living conditions of people who suffer from them should be addressed in widely available media (i.e., increasing the level of knowledge and awareness in the whole society as well as conveying information about aid available to people with mental illnesses;

holding integration meetings and special events that activate people with illnesses and their families, acquaintances and the local community; taking more community measures and establishing community treatment centers; establishing supervised apartments.

The described research has identified that the amount and range of sources and types of support that is offered to people with mental illnesses was evaluated positively by the vast majority of subjects representing all the researched groups. A problematic issue is the low accessibility of professional support, which stems from the mental health protection system being underfunded. This translates into lower effectivity of health promotion, diagnostics and treatment. The society also represents a very low level of knowledge regarding mental disorders. This hinders social and professional activation of people with illnesses. Another huge problem is the underinformation of caretakers of people with mental illnesses. These people hardly ever seek help. They usually possess very limited knowledge regarding possibilities to obtain help, nor do they usually report training needs. Thus, targetting educational and information activities at this group is essential as it would translate directly into the situation of people with illnesses.

An equally important task that needs to be carried out is increasing the society's awareness with regard to mental illnesses and people who suffer from them as well as their families. Taking actions of this kind enables increasing people's awareness of disease identification and, at the same time, the probability of early diagnosis and treatment onset, which, in turn, inhibits results of the illness. At the same time, informing the society and improving knowledge on mental illnesses allows changing attitudes towards people who suffer from them. This is an action that, in the long term, allows people with mental illnesses and their families to function in a fuller manner. It is especially important in the context of such people's treatment and social rehabilitation. People with mental illnesses often struggle with their problems for a long time, for some illnesseseven their whole lives. Through increasing the awareness of this type of illnesses it is possible to improve the situation of people who suffer from them (with respect to, e.g., labor market). Moreover, people's social environments play a crucial role in identifying mental illnesses. The increase in knowledge regarding illnesses' prevalence and symptoms is a crucial element of prevention, which may enable psychiatric intervention at a very early stage of the illness, and, thus, reduce its' results.

\section{Standards and change directions in mental health protection and guidelines for helping people with mental disorders}

Psychiatry and clinical psychology, as applied disciplines of mental health protection that are also concerned with specialist education of psychiatrists and clinical psychologists, need to accommodate the current general developmental goals for mental health protection in European Union countries. Improving psychologists' professional qualifications translates into increasing the quality of services provided to people with mental illnesses. The measures that can be taken by specialist psychiatrists or psychologists support the goals that are pursued in the environments of people with illnesses through noninstitutional structures (i.e., non-governmental organizations or local influences in the environments of people with illnesses). The phenomenon of deinstitutionalization points to a neccesity of including alternative (environmental) forms of help, along with institutional psychiatry, in the treatment of people with mental disorders.

One of the priorities of health policy towards people with illnesses (not only mental ones) is supporting their social inclusion (as opposed to exclusion). This translates into supporting economy that represents high levels of employment, which ensures social and territorial coherence. It is assumed that by 2020 the number of people facing social risks (i.e., poverty and social exclusion) will have decreased by 20 million, while the employment rate in the EU will have increased, reaching $75 \%$. Poland has posited increasing the employment rate for people aged between 20 and 64 to a level of at least $71 \%$ and reducing the number of people at risk of poverty and social exclusion by 1.5 million. Meeting this challenge requires an allencompassing, coordinated approach to protecting health, also the mental one. Interventions within the area of health 
protection are key for reducing the risk of falling into poverty due to professional deactivation caused by loss of health and illnesses (Policy Paper for the protection of health for the period 2014-2020).

In 2014 the Agency for Health Technology Assessment and Tariff System began preparations for working on the valuation of the publicly funded health services. Valuation of psychiatric services was pronounced to be a priority action, obligatory to be taken in 2015. In July 2015 the Coordination Committee for Development Policy adopted the mentioned "National Strategic Framework: Policy Paper for the protection of health for the period 2014-2020". It was approved by the Ministry of Health on 8 July 2015. This document is aimed at fostering the implementation of strategic guidelines for programs cofinanced from European Union funds. In its "Health 2020. A European policy framework and strategy for the 21st century", the WHO Regional Office for Europe points out that good health is essential for economic and social growth. The abovementioned documents point to a necessity to provide proper national strategic frameworks for carrying out the topic areas concerned with health protection.

Mental health protection is an important goal within health policy. The basic goals for mental health protection that were defined within the "Policy Paper for the protection of health for the period 2014-2020" (2015) are, namely:

- promoting mental health and preventing mental disorders (developing health prophylaxis, diagnostics and corrective medicine directed towards the main epidemiological problems in Poland; preventing mental disorders, namely: suicides, depression (formulating programs for preventing depression); increasing the social integration of people with mental disorders,

— ensuring all-encompassing and commonly accessible health care and other care and aid forms essential for people with mental disorders in order to function within a family and social environment,

— counteracting negative demographic trends through developing care for mothers, children and elderly people,

- improving the effectiveness and organization of the healthcare system in the context of a changing demographic and epidemiological situation, and providing support for scientific research, technological advances and innovations within healthcare,

- supporting the system of medical personnel education in the context of tailoring resources to changing social needs,

- developing scientific research and the information system on mental health.

The National Programme for the Protection of Mental Health for 2016-2020 also points to a necessity of pursuing the abovementioned goals.

Having analyzed the mentioned documents that confirm the necessity to promote mental health in the Polish population, mutual directions of seeking solutions for health policy can be identified. These areas are adumbrated below.

(1) Relating the mental health protection oriented measures taken to local communities of a certain territorial level (i.e., region, city, borough, municipality etc.); acknowledging the importance of the manner of perceiving the tasks and obligations of psychiatry and clinical psychology that includes the environments of people with illnesses,

(2) Introducing split responsibility through working in teams of differing professional competences and collaborating with various social ecology agents and social support networks,

(3) Providing all-encompassing services and taking multidirectional measures (diverse methods, different people, various institutions); supporting the establishment of institutional models of professional behaviors that foster implementing the ideas of psychiatry in a so-called "friendly local community"; accommodating the need to educate people who shape public opinion and cultural values,

(4) Relating the measures taken to the integrated model of solving health problems (i.e., multidirectional and multispecialist effort coordination that ensures continuity of psychiatric and psychological care for people with mental disorders),

(5) Accommodating the promotion of education and popularization of good therapy and social rehabilitation tools in order to reduce the sense of professional helplessness and passiveness of people with mental illnesses and their environments. 
Environmental ideas, systems and methods (including non-institutional ones that provide support for environmental psychiatry and the local community) have a lot in common with regard to carrying out a cohesive health policy towards people with diverse mental disorders. Caring for people who face crises or mental disorders is not solely a task of psychiatry or clinical psychology —it is a task of the whole community in which these people and their families function.

People who face various mental disorders that require medical and social (i.e., school, workplace or other community) interventions have mutual types of social (environmental) bonds. Those are, firstly, family bonds-these people are members of a primary support group. Secondly, bonds tie them with a given state (people with mental illnesses are citizens and members of a law-regulated community of local or supralocal interests.) Thirdly, people with illnesses are participants within a cultural community, i.e. a certain system of beliefs and meanings that denote shared views, behaviors and values (Wciórka, 2000).

Thus, carrying out health policy towards people with mental disorders would require including both therapeutic and social aspects of offering aid within mental health protection.

\section{Summary}

Pursuing the aims of health policy should involve the diversity of patients' social bonds. The National Programme for the Protection of Mental Health, the Act on Mental Health Protection and the "National Strategic Framework: Policy Paper for the protection of health for the period 2014-2020" accommodate mutual (similar) goals that implicate prognoses for improving healthcare for people with mental illnesses. As it is asserted in these documents, prophylaxis and healthcare in the upcoming years will form a system oriented towards a necessity to accommodate living longer in full health and respect the varying psychosocial needs of today's and future people (i.e., clients, patients). All investments in health policy and infrastructure ought to be made with regard to the diagnosed deficits. They should also provide support for improving the effectiveness of the whole health system. Thus, the diagnosis of the aid and social support system for people with mental disorders may constitute a vital element for improving the effectiveness of the health system for this group of people with illnesses.

\section{Literature}

[1] Information on the implementation of actions stemming from the National Programme for the Protection of Mental Health in 2014. Ministry of Health, Warsaw, 2015.

[2] National Strategic Framework: Policy Paper for the protection of health for the period 2014-2020. Warsaw, July 2015. Ministry of Health.

[3] 2008-2035 population projection for Poland, Central Statistical Office of Poland, Warsaw

[4] 2008,.3,http://stat.gov.pl/cps/rde/xbcr/gus/L_prognoza_ludnosci_PL_2008-2035.pdf.

[5] Act on Mental Health Protection of 1994. Polish Journal of Laws 2016, item 546

[6] Wciórka J. Psychiatria środowiskowa: idea, system, metoda i to (Environmental psychiatry: The idea, system, method and background). Postępy Psychiatrii i Neurologii, 2000, 9, 319-337.

[7] Sytuacja zdrowotna ludności Polski i jej uwarunkowania (The health situation of the Polish populace and its determinants), editors: Bogdan Wojtyniak, Paweł Goryński, Bożena Moskalewicz, National Institute of Public Health - National Institute of Hygiene, Warsaw, 2012.

[8] The Program for Counteracting Selected Health Problems in the Mazovia Province and the Mazovian Program for Mental Health Protection.

[9] Piotr Nowak-Skyrpan, Agnieszka Patrzałek, Tomasz Błacha, Ireneusz Lemański, Danuta Książek, Marek Siwecki, Diagnosis of the social support system for people with mental disorders within services for helping and social integration in Mazovia, Observatory of Social Integration.

[10] Report for the Ministry of Labour and Social Policy for I-XII on the biannual and annual social benefits-in cash, in kind and in services, by Anna Kasperska.

[11] Summary of the "Diagnozing the help and social support system for people with mental illnesses in the Mazovia Province" research project carried out by EU-CONSULT Sp. z o.0. as commissioned by the Mazovian Center for Social Welfare Policy. The project was co-financed from the resources of the Human Capital Operational Programme (as part of European Union's European Social Fund). 